\title{
Escherichia coli productor de toxina Shiga en carnes molidas y chacinados embutidos de Corrientes, Argentina
}

\author{
Cicuta, M.E. ; Deza, N.L. ${ }^{3}$; Roibón, W.R. ${ }^{1}$; Arzú, O.R. ${ }^{2}$; Barceló, M.C.1 \\ Cátedras de Microbiología y Bromatología ${ }^{2}$, Facultad de Ciencias Veterinarias, UNNE, Sargento Cabral 2139, \\ Corrientes (3400), Argentina. Tel/Fax 03783-425753, E-mail: cicuta@vet.unne.edu.ar. Servicio Fisiopatogenia ${ }^{3}$, \\ Instituto Nacional de Enfermedades Infecciosas - ANLIS "Dr. Carlos G. Malbrán”, \\ Av. Vélez Sarsfield 563 (1281), Buenos Aires. E-mail: ndeza@anlis.gov.ar.
}

\begin{abstract}
Resumen
Cicuta, M.E.; Deza, N.L.; Roibón,W.R.; Arzú, R.O.; Barceló, M.C.: Escherichia coli productor de toxina Shiga en carnes molidas y chacinados embutidos de Corrientes, Argentina. Rev. vet. 20:1, 11-14, 2009. Escherichia coli productor de toxina Shiga (STEC) causa casos esporádicos y brotes de diarrea con o sin sangre y síndrome urémico hemolítico. El serotipo O157:H7 es prevalente, pero existen otros serotipos como O26:H11; O103:H2; O111:NM; O121:H19 y O145:NM asociados a enfermedad humana severa. Los rumiantes en general y el ganado vacuno en particular, han sido señalados como los principales reservorios de $S T E C$, y los alimentos de origen cárnico como el vehículo más frecuente. Entre octubre de 2006 y noviembre de 2008 se analizaron bacteriológicamente 246 muestras (206 de carne molida bovina y 40 de chacinados embutidos). Luego de la caracterización bioquímica de las colonias de E. coli se realizó la técnica de PCR múltiple, para detección de los genes $s t x_{1} / s t x_{2}$ y $r f b_{\mathrm{O}_{57}}$. La caracterización genotípica de los factores de virulencia accesorios eae y exhA también se realizó por PCR. Se identificaron 172 cepas E. coli (139 de 88 muestras de carne molida y 33 de 19 embutidos); sólo en una muestra de carne molida se aisló $E$. coli STEC O174:H21, stx $x_{2}$ eae negativo y exhA positivo, sensible a los antibióticos ensayados. A partir de una muestra de carne molida también se detectó una cepa O157:NM no toxigénica siendo sus factores de virulencia accesorios eae y ehxA negativos. Cepas stx $x_{2}$ como la de este trabajo, han sido predominantes en varios estudios llevados a cabo en Argentina sobre bovinos y sus productos, en especial carnes molidas y hamburguesas.
\end{abstract}

Palabras clave: bovino, Escherichia coli, Shigatoxina, carne molida.

\begin{abstract}
Cicuta, M.E.; Deza, N.L.; Roibón,W.R.; Arzú, R.O.; Barceló, M.C.: Shiga toxin-producing Escherichia coli in ground beef and sausages from Corrientes, Argentina. Rev. vet. 20: 1, 11-14, 2009. Shiga toxin-producing Escherichia coli (STEC) causes sporadic outbreaks of non-bloody and bloody diarrhea, and hemolytic uremic syndrome (HUS). E. coli O157:H7 is the most prevalent STEC serotype. However, other serotypes such as O26:H11; O103:H2; O111:NM; O121:H19 and O145:NM may cause a similar disease spectrum. Ruminants, especially cattle, and their beef products, are the most important reservoirs of STEC. From October 2006 to November 2008, two hundred and forty six samples (206 minced beef and 40 sausages) were analysed bacteriologically. After biochemical characterization of $E$. coli, multiplex PCR was performed in order to detect $s t x_{1} / s t x_{2}$ and $r f b_{0157}$ genes. PCR was carried out to determine additional virulence factors such as eae and exhA. One hundred and seventy two E. coli strains were identified (139 from 88 minced beef samples and 33 from 19 sausages), one STEC O174:H21, stx $x_{2}+$, exhA +, eae - and one non-toxigenic O157:NM, eae and $e h x A$ negatives were isolated from minced beef samples. Strains $s t x_{2}$ are predominant in cattle and swine in Argentina, especially in their derivates such as minced beef and hamburgers.
\end{abstract}

Key words: cattle, Escherichia coli, Shiga toxin, minced beef. 


\section{INTRODUCCIÓN}

Escherichia coli productor de toxina Shiga (STEC) es un patógeno emergente en humanos transmitido por alimentos, asociado a casos esporádicos y a brotes de diarrea con o sin sangre, colitis hemorrágica y síndrome urémico hemolítico (SUH) ${ }^{21}$. En Argentina la OMS considera que el SUH es endémico, con 400 casos nuevos por año ${ }^{21,25}$. Si bien la mayoría de los estudios están orientados a la detección de STEC O157, en la actualidad aumentaron los esfuerzos para detectar los diferentes serotipos de $S T E C$ no-O157 5, 10, 24 . La principal vía de transmisión de STEC O157 y no-O157 son los alimentos contaminados, como por ejemplo, carne molida, productos cárnicos crudos o insuficientemente cocidos, hamburguesas, embutidos fermentados, morcilla, leche no pasteurizada, yogur, quesos, mayonesa, papas, lechuga, brotes de soja y alfalfa, jugos de manzana no pasteurizados y agua, entre otros $1,4,15,20$.

La contaminación de los alimentos se debe principalmente al contacto con las heces del ganado bovino 9, 10 . En la Argentina, se detectó STEC no-O157 en el $8,4 \%$ de hamburguesas supercongeladas ${ }^{6} \mathrm{y}$ STEC $O 157$ en el 3,9\% de productos cárnicos a nivel de boca de expendio ${ }^{2}$. Otras formas de transmisión incluyen el contacto directo del hombre con los animales, la contaminación cruzada durante la preparación de alimentos y la transmisión persona a persona por la ruta fecal-oral ${ }^{10}$. Es importante destacar que la dosis infectiva capaz de ocasionar enfermedad por parte de este grupo bacteriano es de 10 a 100 bacterias por gramo de alimento.

Dado que los perfiles de virulencia de Escherichia coli aisladas de hamburguesas y carne molida se corresponden con los obtenidos de terneros y bovinos adultos ${ }^{16}$ y debido a la detección de una cepa STEC no-O157:H7 a partir de una muestra de carne bovina molida ${ }^{4} \mathrm{y}$ varios tipos toxigénicos de la misma bacteria a partir de lechones en investigaciones anteriores ${ }^{3,17}$, el propósito del presente trabajo fue ampliar la búsqueda de E. coli productor de toxina Shiga, a partir de carnes molidas y embutidos del nordeste argentino, a fin de establecer su probable papel en la transmisión.

\section{MATERIAL Y MÉTODOS}

En el período comprendido entre octubre de 2006 y noviembre de 2008 se analizaron bacteriológicamente 246 muestras (206 de carne molida bovina y 40 de chacinados embutidos) provenientes de la provincia de Corrientes, Argentina. Cada unidad se conformó de acuerdo con la normativa del Código Alimentario Argentino ${ }^{12}$, de porciones representativas de $65 \mathrm{~g} \mathrm{sem}$ bradas en $585 \mathrm{ml}$ de agua peptonada con cefixima $(0,05$ $\mathrm{mg} / \mathrm{l})$ a $37^{\circ} \mathrm{C}$ durante $6 \mathrm{~h}$ y luego aisladas en agar eosina azul de metileno.

La caracterización bioquímica de las colonias fermentadoras de lactosa se realizó mediante la utilización de citrato de Koser y la producción de lisina decarboxilasa en agar lisina hierro. Con esta identificación previa se hicieron las pruebas de crecimiento en presencia de telurito de potasio, fermentación de sorbitol y detección de $\beta$-glucuronidasa. Los aislamientos confirmados como E. coli se enriquecieron en caldo tripticasa de soja a $37^{\circ} \mathrm{C}$ por $6 \mathrm{~h}$ y posteriormente fueron sembrados en agar MacConkey sorbitol (SMAC).

Las placas de $S M A C$ se incubaron a $37^{\circ} \mathrm{C}$ durante 18-24 h. Como tamizaje se realizó la técnica de $P C R$ múltiple ${ }^{7,8}$ de la zona de crecimiento confluente, para detección de los genes $s t x_{1,} s t x_{2}$ y $r f b_{0157}$ usando los oligonucleótidos ya descriptos ${ }^{18,19}$. Los aislamientos $s t x$ positivos fueron identificados por técnicas bioquímicas estándares, serotipificados usando antisueros de $E$. coli $\mathrm{O}$ y H ${ }^{14}$ y caracterizados feno-genotípicamente. Los genes eae y ehxA fueron detectados por la técnica de $P C R^{7,22}$ y la hemólisis debida a $E H E C$-enterohemolisina se detectó en placas de agar sangre con glóbulos rojos desfibrinados de oveja.

El antibiotipo fue determinado según el método de Kirby Bauer ${ }^{13}$ para ácido nalidixico, amikacina, ciprofloxacina, ampicilina, cloranfenicol, colistin, estreptomicina, gentamicina, nitrofurantoína, tetraciclina y trimetoprima-sulfametoxazol y serotipificados usando antisueros de $E$. coli $O$ y $H^{14}$. Las variantes de $s t x_{2}$ se determinaron por análisis de polimorfismo de longitud de los fragmentos de restricción (RFLP) de los productos de amplificación obtenidos por $P C R$ de una región de la subunidad B de la toxina ${ }^{23}$.

\section{RESULTADOS Y DISCUSIÓN}

Se identificaron un total de 172 cepas E. coli (139 de 88 muestras de carnes molidas y 33 de 19 embutidos). Proporcionalmente y a pesar del bajo número de embutidos procesados, hubo similares aislamientos de ambos tipos de muestras: $63,3 \%$ en carnes molidas y $57,6 \%$ a partir de embutidos, a diferencia de muestreos

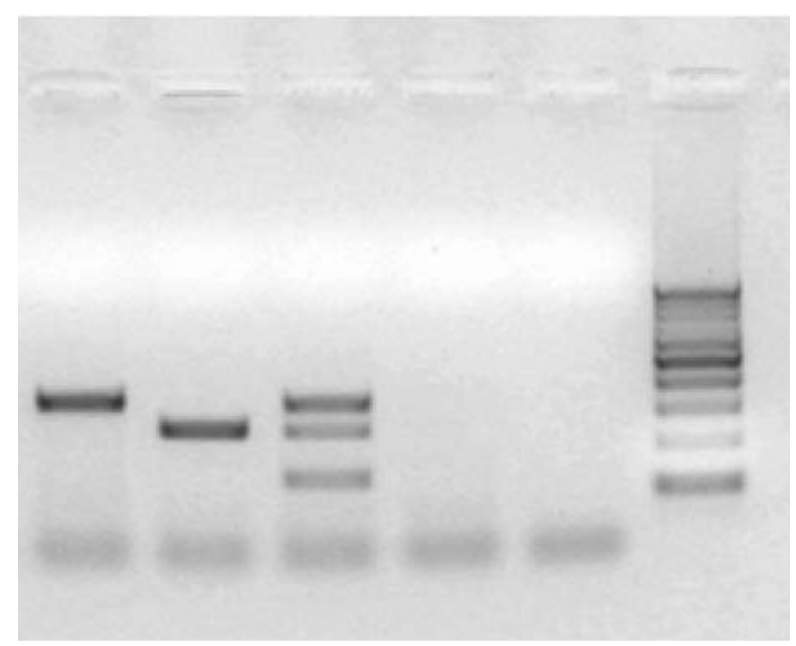

Figura 1. Línea 1: E.coli O174:H21 stx. Línea 2: E.coli O157:NM. Línea 3: control positivo E.coli EDL933 $s t x_{1} / s t x_{2} / r f b_{O I 57}$. Línea 4: control negativo E.coli ATCC 25922 sin factores de virulencia. Línea 5: control de reactivos. Línea 6: marcador de tamaño molecular Cien Marker. 
anteriores donde se notaba mayor contaminación en los últimos ${ }^{3}$. La cepa aislada de carne molida fue caracterizada como E. coli $\mathrm{O} 174: \mathrm{H} 21$, stx 2 por la técnica de $P C R$ múltiple (Figura 1), negativa para el marcador de virulencia eae (Figura 2) y positivo para el gen exhA (Figura 3), fermentadora de sorbitol, $\beta$-glucuronidasa positiva y sensible a los antibióticos ensayados. Se detectó además, a partir de otra muestra de carne molida, una cepa O157:NM no toxigénica siendo sus factores de virulencia accesorios eae y ehxA negativos (Figuras 2 y 3 ).

Debido a que el tipo 2 de toxina Shiga $\left(s t x_{2}\right)$ es el principal responsable de la falla renal en el $\mathrm{SUH}^{21}$, es necesario extremar los controles higiénico-sanitarios en derivados bovinos, en especial carne molida, para que no constituyan riesgo en los consumidores. Cepas st $x_{2}$ como la de este trabajo han sido predominantes en varios estudios llevados a cabo en Argentina ${ }^{1,4,6}$ sobre bovinos y sus productos, en especial carnes molidas y hamburguesas, hallándose sin embargo un $60 \%$ de STEC no-O157 productoras de toxina Shiga stx ${ }_{1}$, en 15 cepas aisladas de 12 muestras de materia fecal diarreica de terneros de establecimientos pampeanos argentinos ${ }^{10}$.

En estudios realizados en la década de 1990, se encontraron evidencias de infección por STEC en el 59\% de los casos de SUH y E. coli O157 fue el serogrupo prevalente ${ }^{11}$. En el año 2005, veintidós Unidades Centinela para la vigilancia del SUH comenzaron a funcionar en las jurisdicciones con las tasas de incidencia más elevadas.

La implementación de estrategias de prevención y control de impacto en Salud Pública son fundamentales para disminuir la morbi-mortalidad asociada al SUH, tal como lo enfatiza la Organización Mundial de la Salud. Por lo tanto, es necesaria la incorporación

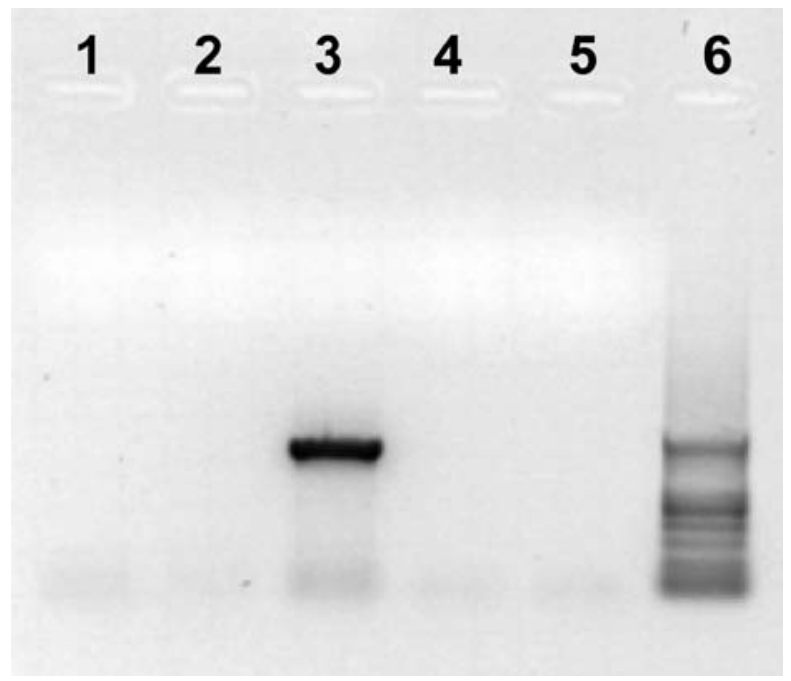

Figura 2. Línea 1: E.coli O174:H21 eae (-). Línea 2: E.coli O157:NM eae (-). Línea 3: control positivo E.coli 2348/68 eae + (EPEC). Línea 4: control negativo E.coli ATCC 25922 sin factores de virulencia. Línea 5: control de reactivos. Línea 6: marcador de tamaño molecular Cien Marker. de medidas de control del patógeno a lo largo de la cadena agro-alimentaria para asegurar la calidad de los alimentos y programas de educación para la salud sostenidos, destinados a la comunidad en general, alertando sobre los riesgos de este agente, sus vías de transmisión y las estrategias de prevención que deben aplicarse.

Agradecimientos: A la Prof. M.C. Benitez, por la colaboración prestada. A SGCYT - UNNE por el apoyo económico brindado (PI 061/2006).

\section{REFERENCIAS}

1. Blanco M, Padola NL, Kruger A, Sanz ME, Blanco JE, Gonzalez EA, Dahbi G, Mora A, Bernardez MI, Echeverría AI, Arroyo GH, Lucchesi PM, Parma AE, Blanco J. 2004. Virulence genes and intimin types of Shigatoxin-producing Escherichia coli isolated from cattle and beef products in Argentina. Intern Microbiol 7: 269-276.

2. Chinen I, Tanaro JD, Miliwebsky E, Lound LH, Chillemi G, Ledri S, Baschkier A, Scarpin M, Manfredi E, Rivas M. 2001 Isolation and characterization of Escherichia coli $\mathrm{O} 157: \mathrm{H} 7$ from retail meats in Argentina. J Food Protect 64: 1346-1351.

3. Cicuta ME, Parma AE, Viñas MR, Sanz ME, Boehringer SI, Roibón WR, Benitez MC, Barceló MC, Vena MM. 1999/2000. Factores de virulencia de Escherichia coli aisladas de porcinos en Argentina. Rev Vet 10: 11-13.

4. Cicuta ME, Deza N, Roibón WR, Pereyra D, Benitez MC, Arzú RO, Boehringer SI. 2006. Detección de Escherichia coli productor de toxina Shiga en reses bovinas y carne molida de Corrientes, Argentina. Rev Vet 17: 2025.

5. Gioffre A, Meichtri L, Miliwebsky E, Baschkier A, Chillemi G, Romano MI, Sosa Estani S, Cataldi A,

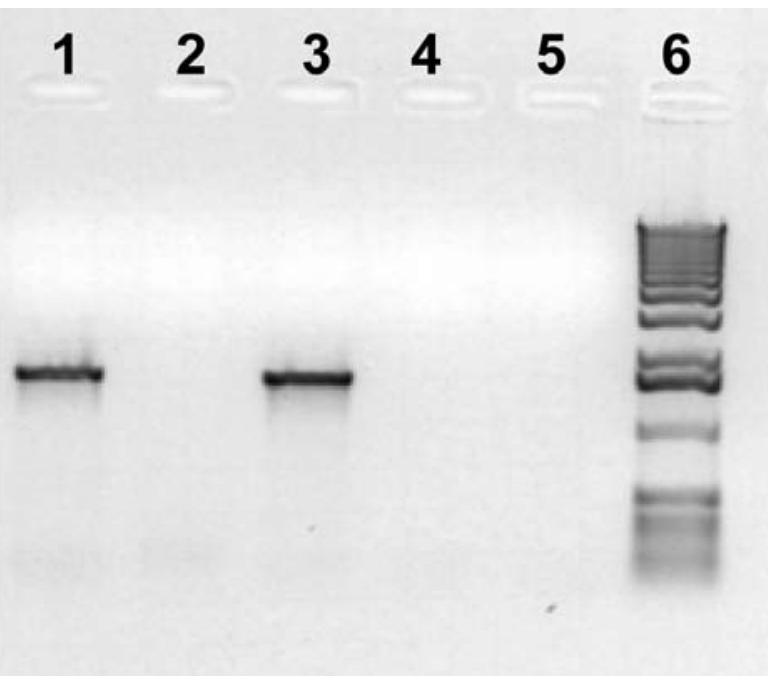

Figura 3. Línea 1: E.coli O174:H21 ehxA (+). Línea 2: E.coli O157:NM ehxA (-). Línea 3: control positivo E.coli E32511 EHEC-ehxA. Línea 4: control negativo E.coli ATCC 25922 sin factores de virulencia. Línea 5: control de reactivos. Línea 6: marcador de tamaño molecular $1 \mathrm{~Kb}$. 
Rodriguez R, Rivas M. 2002. Detection of Shiga toxin Escherichia coli by PCR in cattle in Argentina. Evaluation of two procedures. Vet Microbiol 22: 301-313.

6. Gómez D, Miliwebsky E, Fernandez Pascua C, Baschkier A, Manfredi E, Zotta M, Nario F, Piquin A, Sanz M, Etcheverria A, Padola N, Parma A, Rivas M. 2002. Aislamiento y caracterización de Escherichia coli productora de verotoxina de hamburguesas supercongeladas y quesos blandos. Rev Arg Microbiol 34: 66-71.

7. Karch H, Bohm H, Schmidt H, Gunzer F, Aleksic S, Heesemann J. 1993. Clonal structure and pathogenicity of Shiga-like toxin-producing, sorbitol-fermenting Escherichia coli O157:H7. J Clin Microbiol 31: 1200-1205.

8. Leotta GA, Chinen I, Epszteyn S, Miliwebsky E, Melamed IC, Motter M, Ferrer M, Marey E, Rivas M. 2005. Validación de una técnica de $P C R$ múltiple para la detección de Escherichia coli productor de toxina Shiga. Rev Arg Microbiol 37: 1-10.

9. Meichtri LH, Miliwebsky E, Gioffré A, Chinen I, Baschkier A, Chillemi G, Guth BE, Masana MO, Cataldi A, Rodríguez HR, Rivas M. 2004. Shiga toxin-producing Escherichia coli in healthy young beef steers from Argentina: prevalence and virulence properties. Int J Food Microbiol 96: 189-198.

10. Mercado EC, Gioffre A, Rodriguez SM, Cataldi A, Irino K, Elizondo AM, Cipolla AL, Romano MI, Malena R, Mendez MA. 2004. Non-O157 Shiga-toxin producing Escherichia coli isolated from diarrhoeic calves in Argentina. J Vet Med B Infect Dis Vet Public Health 51: 82-88.

11. Miliwebsky ES, Balbi L, Gómez D, Wainsztein R, Cueto Rúa M, Roldán C, Calleti M, Leardini NA, Baschkier A, Chillemi GM, Rivas M. 1999. Síndrome urémico hemolítico en niños de Argentina: asociación con la infección por Escherichia coli productor de toxina Shiga. Bioq Patol Clín 63: 113-121.

12. Ministerio de Salud de la Nación. Código Alimentario Argentino actualizado. Ley 18.284. On line: http://www. anmat.gov.ar/CODIGOA/CAA1.HTM.

13. National Committee for Clinical Laboratory Standards. 2005. Performance standards for antimicrobial disk susceptibility tests, $8^{\text {th }}$ ed., Wayne (USA), p. 24.

14. Ørskov F, Ørskov I. 1984. Serotyping of Escherichia coli. In: Methods in Microbiology (Bergan T, Ed.), Academic Press, London, 14; 43-112.

15. Oteiza JM, Chinen I, Miliwebsky E, Rivas M. 2006. Isolation and characterization of Shiga toxin-producing EScherichia coli from precooked sausages (morcillas). Food Microbiol 23: 283-288.
16. Parma AE, Sanz ME, Blanco JE, Blanco J, Viñas MR, Blanco M, Padola NL, Etcheverría AI. 2000. Virulence genotypes and serotypes of verotoxigenic Escherichia coli isolated from cattle and foods in Argentina. Eur J Epidemiol 16: 757-762.

17. Parma AE, Sanz ME, Viñas MR, Cicuta ME, Blanco JE, Boehringer SI, Vena MM, Roibón WR, Benitez MC, Blanco J, Blanco M. 2000. Toxigenic Escherichia coli isolated from pigs in Argentina. Vet Microbiol 72: 269-276.

18. Paton AW, Paton JC. 1998. Detection and characterization of Shiga toxigenic Escherichia coli by using Multiplex PCR assays for stx1, stx2, eaeA, enterohemorrhagic E. coli hlyA, rfbO111, and $r f b \mathrm{O} 157$. J Clin Microbiol 36: 598-602.

19. Pollard DR, Johnson WM, Lior H, Tyler SD, Rozee KR. 1990. Rapid and specific detection of verotoxin genes in Escherichia coli by the polymerase chain reaction. J Clin Microbiol 28: 540-545.

20. Rivas M, Caletti MG, Chinen I, Refi SM, Roldán CD, Chillemi G, Fiorilli G, Bertolotti A, Aguerre L. 2003. Home-prepared hamburger and sporadic hemolytic uremic syndrome, Argentina. Emerging Infect Dis 9: 11841186.

21. Rivas M, Miliwebsky E, Chinen I, Deza N, Leotta GA. 2006. Epidemiología del síndrome urémico hemolítico en Argentina. Diagnóstico del agente etiológico, reservorios y vías de transmisión. Medicina (Buenos Aires), 66 (Supl. III): 27-32.

22. Schmidt H, Beutin L, Karch H. 1995. Molecular analysis of the plasmid-encoded hemolysin of Escherichia coli O157:H7 strain EDL 933. Infect Immun 63: 1055-1061.

23. Tyler SD, Johnson WM, Lior H, Wang G, Rozee KR. 1991. Identification of verotoxin type 2 variant B subunit genes in Escherichia coli by the polymerase chain reaction and restriction fragment length polymorphism. J Clin Microbiol 29: 1339-1343.

24. Varela G, Chinen I, Gadea P, Miliwebsky E, Mota MI, González S, González G, Gugliada MJ, Carbonari CC, Algorta G, Bernardá M, Sabelli R, Pardo L, Rivas M, Schelotto F. 2008. Detección y caracterización de Escherichia coli productor de toxina Shiga a partir de casos clínicos y de alimentos en Uruguay. Rev Arg Microbiol 40: 93-100.

25. World Health Organization (WHO). 1997. Prevention and control of enterohaemorrhagic Escherichia coli (EHEC) infections. Bull World Health Organ 76: 245255. 